\title{
ATITUDES ACERCA DA PESQUISA CIENTIIFICA ENTRE ESTUDANTES DE ENFERMAGEM DE TREES ESCOLAS DO INTERIOR DO ESTADO DE SÃO PAULO
}

\author{
ATITUDES TOWARDS CIENTIFICAL RESEARCH AMONG NURSERY STUDENTS FROM \\ THREE SCHOOLS FROM THE SÃO PAULO COUNTRYSIDE \\ ACTITUDES ACERCA DE LA PESQUISA CIENTÍFICA ENTRE ESTUDIANTES DE \\ ENFERMERÍA DE TRES ESCUELAS DEL INTERIOR DEL ESTADO DE SÃO PAULO \\ Liliane Passarelli Rodrigues ${ }^{1}$ \\ Silvia Helena De Bortoli Cassiani
}

\begin{abstract}
RESUMO: A iniciação científica proporciona o desenvolvimento do pensamento lógico e crítico, fatores importantes na formação profissional, portanto a necessidade da exposição às atividades de pesquisa desde início do curso universitário. Este estudo quantitativo, identificou as atitudes sobre a pesquisa científica de alunos de Enfermagem. Foram investigados 248 alunos cursando $1^{\circ}, 3^{\circ}$ e $8^{\circ}$ semestres em três escolas de enfermagem localizadas em cidades do interior paulista. Foram utilizados Escala de Likert como instrumento de coleta de dados. Dos dados analisados realizou-se uma comparação entre as respostas colhidas nos diferentes semestres. Concluímos que desde o $1^{\circ}$. semestre os alunos possuem atitudes responsáveis frente à pesquisa, sendo no $1 \%$ semestre menos conscientes da importância dos resultados de pesquisa comparados à intuição e experiência pessoal. Possuem ainda interesse em discutir os resultados de pesquisa com os colegas. A maioria dos alunos investigados concordam que é fundamental ao aluno a prática de investigação científica junto a seus professores.
\end{abstract}

PALAVRAS CHAVE: Alunos de Graduação em Enfermagem, Pesquisa Científica, Pesquisa

ABSTRACT: The nursing research among undergraduate students develop the logical and critical thinking that are important to the professional. So, it is necessary to have content about research in the beginning of the undergraduate courses. The quantitative study identified the attitudes about nursing research of the undergraduate students. It was investigated 248 undergraduate students of the $1^{\circ}$., $3^{\circ}$. $8^{\circ}$. semesters in three nursing schools of the São Paulo State. It was utilized Likert Scales as a instrument of data collection. The results showed that the students have responsible attitudes of the research: The students from the $1 \%$. semesters are less conscious about the results of research comparable to the intuition and personal experience. They are interested in of discuss the results of the research with colleagues. Most of the students agree that is fundamental to conduct research with the faulty members.

KEYWORDS: Undergraduate students, Nursing Research, Research

${ }_{1}$ Aluna do 8으., semestre do curso de graduação da Escola de Enfermagem de Ribeirão Preto - Universidade de São Paulo - Bolsista de Iniciação Científica do Programa Interinstitucional de Bolsas de Iniciação Científica do CNPq (PIBIC-CNPq)

${ }^{2}$ Professora Doutora do Departamento de Enfermagem Gerale Especializada da EERP-USP.

R. Bras. Enferm. Brasília, v. 51, n . 4, p. 589-601 out./dez. 1998 
RESUMEN: La iniciación científica proporciona el desarrollo del pensamiento lógico y crítico, factores importantes en la formación profesional. Por eso es necesario introducir actividades de pesquisa desde el inicio de los cursos universitarios. Este estudio cuantitativo identificó las actitudes de los alumnos de enfermería al respecto de pesquisa científica. Fueron investigados 248 alumnos, cursando $1^{\circ}, 3^{\circ}$ y $8^{\circ}$ semestres en tres escuelas de enfermería localizadas en ciudades del interior paulista. Fue utilizada escala de Likert como instrumento de recolecta de datos. Con los datos analisados, se realizó una comparación entre las respuestas obtenidas en los diferentes semestres. Se concluyó que desde el primer semestre los alumnos poseen actitudes responsables frente a la pesquisa, pero son menos concientes de la importancia de los resultados comparados a la intuición y a la experiencia personal.Tienen, además, interés en discutir los resultados de pesquisa com los compañeros. La mayoria de los alumnos están de acuerdo en que es fundamental conducir la práctica de investigación científica con sus profesores.

PALABRAS CLAVE: Estudiantes de enfermería, pesquisa científica, pesquisa

\section{INTRODUÇÃO}

Há um relativo consenso na literatura que a exposição às atividades de pesquisa devem ser iniciadas já nos primeiros anos dos cursos universitários, uma vez que resulta em aumento no uso de conteúdo e métodos aprendidos nas disciplinas subseqüentes. A exposição inicial cria mais oportunidades para uma socialização efetiva através de experiências de aprendizagem, relativas às abordagens críticas e o uso da pesquisa em situações clínicas além de propiciar o desenvolvimento do pensamento lógico e crítico.

Entretanto, acredita-se que o estudo dos problemas da realidade de forma científica e gerado por uma motivação intrínseca dos alunos é o instrumento mais apropriado para promover sua aprendizagem. Através da análise crítica de problemas da realidade, o aluno pode observar, analisar, criticar e buscar informações, a fim de escolher alternativas, apresentar, propor e executar soluções, modificando ou contribuindo para a modificação de processos ou elementos desse ambiente social do qual ele é parte.

A atividade de participação na condução de pesquisa científica em colaboração com os docentes, tem se destacado e motivado os alunos nos cursos de graduação em enfermagem. Para tanto, muitos recebem auxílio financeiro de vários órgãos governamentais brasileiros, sob a forma de bolsas de iniciação científica, para participarem de projetos propostos pelos investigadores e professores. As bolsas de iniciação científica visam proporcionar ao bolsista a aprendizagem de técnicas e métodos científicos, induzindo o questionamento crítico e o espirito científico.

Em 1996, aproximadamente 35\% dos alunos de graduação da Escola de Enfermagem de Ribeirão Preto, estavam engajados em projetos de investigação conduzidos por docentes, despertando nestes o reconhecimento da investigação científica como uma forma de desenvolver os conhecimentos. Entretanto, somente aqueles alunos com iniciativa para procurarem os docentes ou que se destacam no curso, e por isso são convidados por docentes, é que estão tendo tais oportunidades. É preciso pois, estender esta atividade a um número maior de alunos.

A Organização Mundial da Saúde (1994) através de seus grupos de estudos em enfermagem tem enfatizado em várias publicações a importância da investigação em enfermagem. Estes Grupos de Estudos indicam que as enfermeiras devem 
conhecer os resultados das investigações e ser capazes de avaliá-los, atribuindo a relativa importância da investigação para o exercício profissional. As enfermeiras devem ainda ser capazes de compreender os benefícios da investigação para si mesmas e para o grupo de clientes por elas atendidos. A OMS (1994) ainda indica ser mister preparar as enfermeiras em técnicas de investigação a fim de que possam participar em pé de igualdade com investigadores nas equipes multi-disciplinares, participando da formulação de problemas de investigação e a realização das mesmas.

A investigação deve pois, converter-se em um processo intrínseco e contínuo da vida assistencial e docente da enfermeira, a fim de melhorar a qualidade da assistência de saúde mediante a introdução de modelos novos e pertinentes. (Ospino, 1994). É pois de importância impar a introdução de atividades de pesquisa científica já nos cursos de graduação. Entretanto, como tem sido as atitudes dos alunos frente às atividades de pesquisa?

Ricci; Cassiani (1994) conduziram estudo identificando o conhecimento que alunos dos cursos de graduação em enfermagem e farmácia tinham acerca do conceito e finalidade da pesquisa, bem como o interesse em desenvolvê-la. 0 estudo mostrou que os alunos vêem a pesquisa científica como aprofundamento e extensão de conhecimento e indicam sua finalidade como a de primordialmente trazer benefícios para melhorar a qualidade de vida da população. Entretanto argumentam não ter informações sobre como iniciar um trabalho científico, embora se interessariam em desenvolver pesquisa.

A literatura é clara e quase unânime ao apontar que o ensino dos métodos de pesquisa deve iniciar a nível da graduação a fim de que possam ser suficientemente assimilados pelos alunos. (Carnegie, 1974, Rodgers; Cowles, 1990). Os objetivos do componente pesquisa no curso de graduação devem enfatizar : o desenvolvimento de uma atitude positiva sobre pesquisa, o desenvolvimento de uma atitude questionadora frente à prática de enfermagem, habilidades para ler criticamente a literatura de enfermagem e habilidade para avaliar os resultados de pesquisa para sua utilização na prática.

Além deste estudo citado, existem poucos estudos publicados na literatura nacional que examinam e avaliam quais são as atitudes de alunos frente à pesquisa científica. (Padilha; Carvalho, 1993). Entretanto tais estudos não analisam atitudes no decorrer dos anos e no curso das disciplinas da graduação como é proposta deste que ora realizamos.

\section{OBJETIVOS}

A condução deste estudo atingiu os seguintes objetivos :

- Identificar as atitudes sobre a pesquisa científica em alunos cursando o 1 , $3^{\circ}$ e $8^{\circ}$ semestres de cursos de graduação em enfermagem.

- Analisar e comparar as respostas obtidas entre estes três grupos.

R. Bras. Enferm. Brasília, v. 51, n . 4, p. 589-601 out./dez. 1998 


\section{MATERIAL E MÉTODO}

\subsection{POPULAÇÃO EM ESTUDO}

A população em estudo constou dos alunos cursando o $1^{\circ}, 3^{\circ}$ e e $8^{\circ}$ semestres de três escolas de enfermagem, localizadas em três cidades do interior paulista: Ribeirão Preto, São Carlos e Campinas. A amostra investigada constituiu-se dos alunos que responderam aos instrumentos de coleta de dados.

A escolha do $1^{\circ}$ e $8^{\circ}$ semestres recaiu, por razões óbvias, sobre o fato de colhermos as informações de alunos que estão iniciando e terminando o curso de graduação. A escolha do $3^{\circ}$ semestre deveu-se ao fato de que neste momento, o aluno já teve contato com conteúdo relativo à metodologia científica nas disciplinas cursadas.

Dessa forma foram investigados os alunos cursando os semestres iniciais, finais e no meio do curso de Graduação em Enfermagem.

\subsection{INSTRUMENTOS DE COLETA DE DADOS}

Como instrumento de coleta de dados foram desenvolvidas e utilizadas escalas de Likert, que consistem de uma série de itens aos quais solicita-se ao aluno uma resposta. $\mathrm{Na}$ escala de Likert foram usados itens que pareciam favoráveis ou nitidamente desfavoráveis ao objeto estudado. A cada resposta foi atribuído um valor numérico que indicava o fato de ser favorável ou desfavorável. Portanto os sujeitos deviam responder a cada item, em termos de vários graus de acordo ou desacordo.

Utilizamos essa escala contendo cinco pontos, variando de 1 a resposta mais negativa e 5 a resposta mais positiva.

Um exemplo de escala de Likert utilizada está apresentada abaixo :

QUADRO 1: Escala de Likert com os cinco pontos referentes as respostas menos negativas até as mais positivas:

ITEM: Eu gosto de ler artigos científicos nas revistas especilalizadas.

\begin{tabular}{|c|c|c|c|c|}
\hline 1 & 2 & 3 & 4 & 5 \\
\hline $\begin{array}{c}\text { Desaprovo } \\
\text { inteiramente }\end{array}$ & desaprovo & indeciso & aprovo & $\begin{array}{c}\text { aprovo } \\
\text { inteiramente }\end{array}$ \\
\hline
\end{tabular}

A escala continha itens que cobriam a responsabilidade da enfermeira frente à compreensão de artigos de pesquisa e utilidade das investigações na enfermagem.

Para a construção da escala foram utilizados os seguintes procedimentos:

- Reunião de um "pool" de frases com base na experiência dos investigadores e literatura consultada;

- Seleção das frases pertinentes e mais indicativas da temática;

- Ordenamento das frases seguindo um grau de complexidade;

- Realização de um estudo piloto com seis juizes, sendo três docentes da Escola de Enfermagem de Ribeirão Preto -USP e três graduandos.

O estudo piloto visou verificar a pertinência do instrumento, avaliar validade de conteúdo e a análise dos dados da escala. Após a análise do resultado do estudo piloto, 
o instrumento definitivo foi aplicado na população descrita.

\subsection{PROCEDIMENTOS DE COLETA DE DADOS}

Em setembro de 1996, entramos em contato, por telefone e correio, com os professores coordenadores do curso de graduação das Escolas de Enfermagem, das cidades de Campinas e São Carlos. Após o consentimento, aplicou-se os instrumentos nos alunos do $8^{\circ}$ semestre. Em novembro, recebemos de Campinas 15 instrumentos respondidos e 10, de São Carlos. Em Ribeirão Preto obtivemos 36 instrumentos preenchidos de alunos cursando o $8^{\circ}$ semestre.

Em março de 1997 entramos novamente em contato, por telefone, com os professores, para administrarem os instrumentos nos alunos cursando o $1^{\circ} \mathrm{e}$ 은 semestres. Depois do consentimento, enviamos os instrumentos pelo correio, e a seguir 88 instrumentos preenchidos foram recebidos, sendo 45 de Campinas, 43 de São Carlos e 99 de Ribeirão Preto.

Portanto, obtivemos 105 instrumentos respondidos pelos alunos do $1^{\circ}$ semestre, 82 no $3^{\circ}$ e 61 do $8^{\circ}$ semestre. Foram colhido no $2^{\circ}$ semestre de 1996 , dados referentes aos alunos cursando o $8^{\circ}$ semestre do curso de graduação, e no $1^{\circ}$ semestre de 1997, dados referentes aos alunos cursando o $1^{\circ}$ e $3^{\circ}$ semestres dos cursos. Trata-se de um estudo descritivo cujos dados foram obtidos através de um levantamento de opiniões de estudantes de enfermagem.

\section{ANÁLISE DOS DADOS}

IDENTIFICAÇÃO DOS PARTICIPANTES:

Duzentos e quarenta e oito alunos foram investigados, destes 105 (42,4\%) cursavam o $1^{\circ}$ semestre, $82(33,1 \%)$ o $3^{\circ}$ e $61(24,5 \%)$ o $8^{\circ}$ semestre. Destes alunos investigados, $60(24,2 \%)$ eram da cidade de Campinas, $53(21,4 \%)$ da cidade de São Carlos e 135 (54,4\%) da cidade de Ribeirão Preto.

Quanto à identificação dos participantes, 93,5\% eram do sexo feminino e 6,5\% masculino. $42,3 \%$ eram alunos do $1^{\circ}$ semestre, $33,1 \%$ do $3^{\circ}$ semestre e $24,6 \%$ do $8^{\circ}$ semestre. Quanto à idade dos participantes, $46,8 \%$ estava na faixa etária de 17 a 19 anos, $47,6 \%$ de 20 a 24 anos, 3,2\% de 25 a 29 anos e 2,4\% de 30 a 35 anos. Portanto $94,4 \%$ estava na faixa etária de 17 a 24 anos.

Para melhor apresentação, unimos os itens: desaprovo inteiramente e desaprovo como sendo desaprovação, aprovo e aprovo inteiramente como aprovação da frase, e último como indeciso. Apresentamos os resultados dividindo-os em tópicos conforme apareceram na escala, uma discussão dos resultados e os gráficos e tabelas, que contêm a porcentagem total dos alunos e os resultados dos semestres separadamente.

Os dados quantitativos foram analisados pelo computador (escalas) no programa Microsoft Excel para Windows 95 versão 7.

Apresentamos os resultados de cada item das escalas, a seguir: 


\subsection{ITENS RELATIVOS À CONEXÃO RESULTADOS DE PESQUISA E PRÁTICA}

\section{Experiência Pessoal X Resultados de Pesquisa na Tomada de Decisões}

Verificamos que a maioria dos alunos desaprovaram que a experiência pessoal é mais importante do que os resultados de pesquisa no cuidado de enfermagem. Os alunos do $1^{\circ}$ semestre estiveram mais indecisos sobre tal consideração e a maioria dos alunos do $3^{\circ}$ e $8^{\circ}$ semestres desaprovaram essa afirmação, enquanto que dentre os que aprovaram, a maioria foi do 8. semestre. Isto mostra-nos que consideram importante o conhecimento teórico adquirido e não somente a prática como importantes na assistência de enfermagem.

Veja os resultados no gráfico abaixo:

GRÁFICO 1: Experiência pessoal é mais importante que resultados de pesquisa.

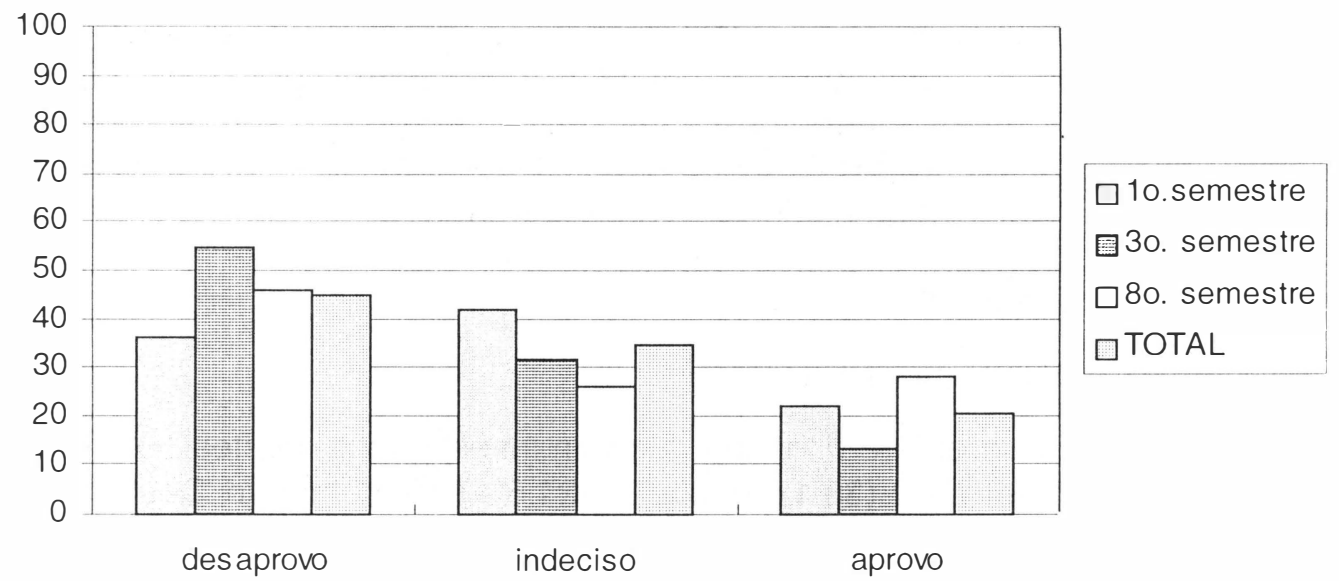

Interessante notar entretanto um ligeiro equilíbrio nas respostas dos anos, com exceção das do $3^{\circ}$ semestre que foram os que mais desaprovaram a afirmação. Nota-se todavia um cotingente de cerca de $30 \%$ de alunos do $8^{\circ}$ semestre que identificam a experiência pessoal como importante. Parece-nos que aproximadamente com a atitude profissional definitiva e as dúvidas acerca do conhecimento prático podem interferido neste resultado.

\section{Pesquisa Científica X Cuidado do Paciente}

No item A pesquisa científica não tem relação direta com o cuidado do paciente mais de $70 \%$ dos alunos dos três semestres diferentes desaprovaram essa afirmação. Entretanto, ainda $26,2 \%$ dos alunos estiveram ir scisos ou aprovaram a falta de relação entre pesquisa científica e o cuidado do paciente. Parece-nos que este é o grupo de alunos que devem nos chamar a atenção nos cursos e investigarmos qual é a razão desta atitude em estudos futuros.

Obtivemos portanto, os seguintes resultados mostrados na Tabela 1: 
TABELA 1: A pesquisa científica não tem relação direta com o cuidado do paciente.

\begin{tabular}{c|c|c|c|c|c}
\hline ESCALA & DESAPROVO & INDECISO & \multicolumn{2}{c|}{ APROVO } & \multicolumn{2}{c}{ TOTAL } \\
\hline & $\%$ & $\%$ & $\%$ & $\%$ & Qtd. \\
\hline $1^{\text {10 Semes. }}$ & 70,78 & 13,33 & 16,19 & 100 & 105 \\
\hline $3^{\text {o }}$ Semes. & 76,83 & 12,20 & 10,98 & 100 & 82 \\
\hline $8^{\circ}$ Semes. & 75,42 & 11,48 & 13,12 & 100 & 61 \\
\hline total \\
(3 semestres) & 73,79 & 12,50 & 13,71 & 100 & 248 \\
\hline
\end{tabular}

\section{Intuição do Enfermeiro X Resultados de Pesquisa na Tomada de Decisões Clínicas}

A maioria dos alunos desaprovaram a afirmação de que a intuição do enfermeiro é mais importante do que os resultados de pesquisa na tomada de decisões clínicas. Notamos que, nos alunos do $1^{\circ}$ semestre houve equilíbrio entre a crença da intuição e a relação de uma pesquisa. Os alunos do $3^{\circ}$ semestre, acreditam que os resultados de pesquisa são mais importantes do que a intuição e mantém-se este valor entre os alunos cursando o $8^{\circ}$ semestre.

O Gráfico 2 apresenta os resultados obtidos:

GRÁFICO 2: A intuição é mais importante que os resultados de pesquisa.

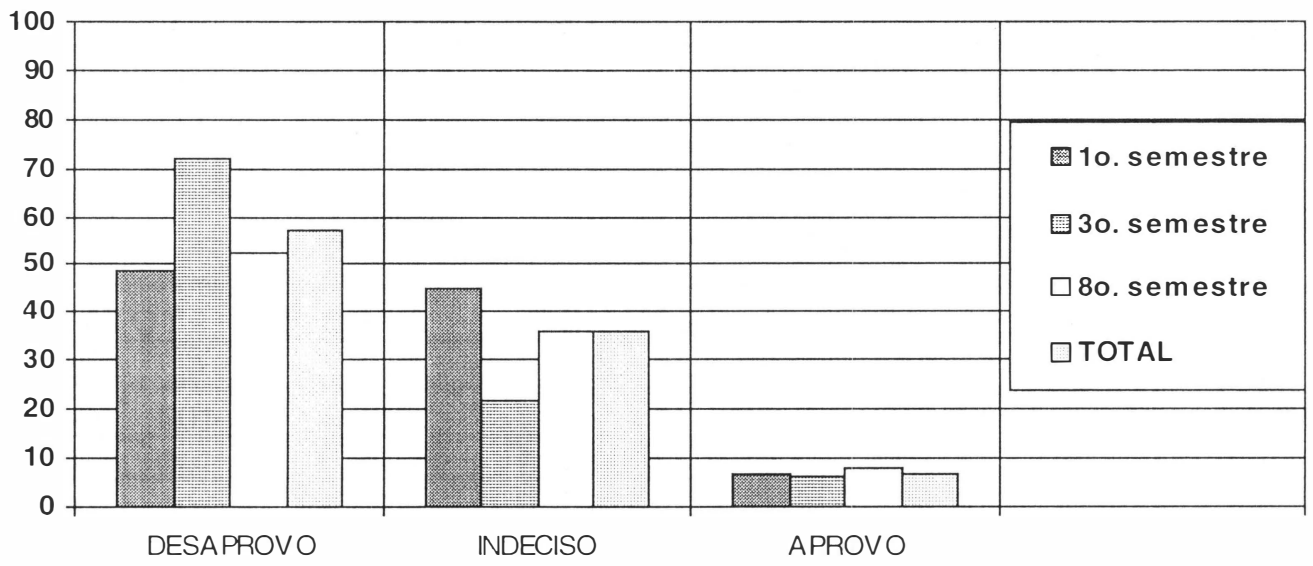

A seguir, descrevemos os itens das escalas que tratam da divulgação dos resultados de pesquisa.

\subsection{DIVULGAÇÃO DOS RESULTADOS DE PESQUISA}

\section{Gostar de Ler Artigos Científicos X Ler Efetivamente Artigos Científicos}

Quanto a gostar da leitura de artigos científicos nas revistas especializadas, observa-se que a maioria dos alunos afirmaram que gostam de ler artigos científicos. Sendo que, em todos semestres, mais de $67 \%$ dos alunos aprovaram tal afirmação. Nota-se, portanto, que da população estudada $72,9 \%$ gostam de ler artigos, sendo que esse sentimento tende a aumentar conforme vão passando os semestres, uma vez que 
$85,2 \%$ dos alunos cursando o $8^{\circ}$ semestre indicam que gostam de ler artigos científicos.

Veja, os dados estão contidos na Tabela 2:

TABELA 2: Eu gosto de ler artigos científicos.

\begin{tabular}{c|c|c|c|c|c}
\hline ESCALA & DESAPROVO & INDECISO & \multicolumn{2}{c}{ APROVO } & \multicolumn{2}{c}{ TOTAL } \\
\hline & $\%$ & $\%$ & $\%$ & $\%$ & Qtd \\
\hline $1^{\circ}$ o Semes. & 15,24 & 17,15 & 67,61 & 100 & 105 \\
\hline $3^{\circ}$ Semes. & 10,98 & 18,28 & 70,74 & 100 & 82 \\
\hline $8^{\circ}$ Semes. & 8,20 & 6,56 & 85,25 & 100 & 61 \\
\hline total & 12,10 & 14,92 & 72,98 & 100 & 248 \\
(3 semestres) & & & & & \\
\hline
\end{tabular}

Sobre a leitura efetiva dos artigos científicos publicados nas revistas $64,92 \%$ dos alunos afirmaram ler artigos científicos. Fazendo uma comparação com as duas afirmações -a de gostar de ler e a de ler artigos científicos definitivamentenotamos quanto aos alunos do $1^{\circ}$ semestre, $67 \%$ afirmam que gostam de ler e quase a mesma quantidade afirmou que lêem realmente os artigos. No $3^{\circ}$ semestre houve uma diferença significativa, dos $70,75 \%$ de alunos que afirmaram gostar de ler, este índice cai para 50\% quanto aos que lêem definitivamente artigos. Questionamos o que ocorre com os 20,75\% dos alunos do 3o semestre que apesar de afirmarem gostar de ler artigos, não os lêem definitivamente. Quanto aos do 8 semestre, há também uma queda do índice entre os $85,25 \%$ que afirmam gostar de ler e os $80,33 \%$ que lêem efetivamente.

Os resultados estão apresentados na Tabela 3:

TABELA 3: Lêem artigos científicos publicados nas revistas.

\begin{tabular}{c|c|c|c|c|c}
\hline ESCALA & DESAPROVO & INDECISO & \multicolumn{2}{c}{ APROVO } & \multicolumn{2}{c}{ TOTAL } \\
\hline & $\%$ & $\%$ & $\%$ & $\%$ & Qtd. \\
\hline 10 Semes. & 15,24 & 17,14 & 67,62 & 100 & 105 \\
\hline $3^{\circ}$ Semes. & 19,51 & 30,49 & 50,00 & 100 & 82 \\
\hline $8^{\circ}$ Semes. & 8,20 & 20,16 & 80,33 & 100 & 61 \\
\hline total & 14,92 & 14,92 & 64,92 & 100 & 248 \\
(3 semestres) & & & & & \\
\hline
\end{tabular}

Estes dados levantam um questionamento sobre o quanto os docentes em suas disciplinas tem encorajado a leitura de artigos científicos.

Quanto ao item: Eu gosto de discutir resultados de pesquisas na classe e com colegas, obtivemos os seguintes resultados.

Dos alunos investigados a maioria aprovaram essa afirmação. Como mostra, na tabela abaixo, mais de 50\% dos alunos de 1ํ e 3o semestres gostam de discutir os resultados de pesquisa com os colegas, sendo que o maior índice de aprovação foi entre os alunos do $1^{\circ}$ semestre e que o índice cai até o $8^{\circ}$. semestre. Observase que entre os alunos do $8^{\circ}$ semestre este percentual não chega a $50 \%$. Questionamos o que levaria a essa diminuição gradativa, do inicio até o final do curso 
de graduação, no que refere à discussão dos resultados de pesquisa entre colegas, quando o que se esperava é que ocorresse justamente o contrário. E qual é portanto, a repercussão no futuro profissional enfermeiro? Será que este índice tende a cair, ainda mais, quando o que esperamos é que houvesse uma tendência para o crescimento?

Obtivemos os seguintes dados, demostrados na Tabela 4:

TABELA 4: Gosto de discutir resultados de pesquisa com colegas.

\begin{tabular}{c|c|c|c|c|c}
\hline ESCALA & DESAPROVO & INDECISO & \multicolumn{2}{c|}{ APROVO } & \multicolumn{2}{c}{ TOTAL } \\
\hline & $\%$ & $\%$ & $\%$ & $\%$ & Qtd. \\
\hline 1ㅇ Semes. & 13,34 & 22,86 & 63,80 & 100 & 105 \\
\hline $3^{\circ}$ Semes. & 21,18 & 24,39 & 54,43 & 100 & 82 \\
\hline $8^{\circ}$ Semes. & 24,58 & 27,87 & 47,55 & 100 & 61 \\
\hline $\begin{array}{c}\text { total } \\
\text { (3 semestres) }\end{array}$ & 19,35 & 24,60 & 56,05 & 100 & 248 \\
\hline
\end{tabular}

\section{Participação em Eventos Científicos Ouvindo Relatos de Pesquisa}

A maioria dos alunos afirmaou gostar de participar, sendo que este total levanos a observar que quase $80 \%$ dos alunos nos três semestres, referem gostar participar de eventos: mais de $72 \%$ dos alunos do $1^{\circ}$ semestre e mais de $80 \%$ dos alunos do $3^{\circ}$ e $8^{\circ}$ semestres.

Os dados coletados serão demostrados abaixo no Gráfico 3:

GRÁFICO 3: Gostar de participar de eventos científicos.

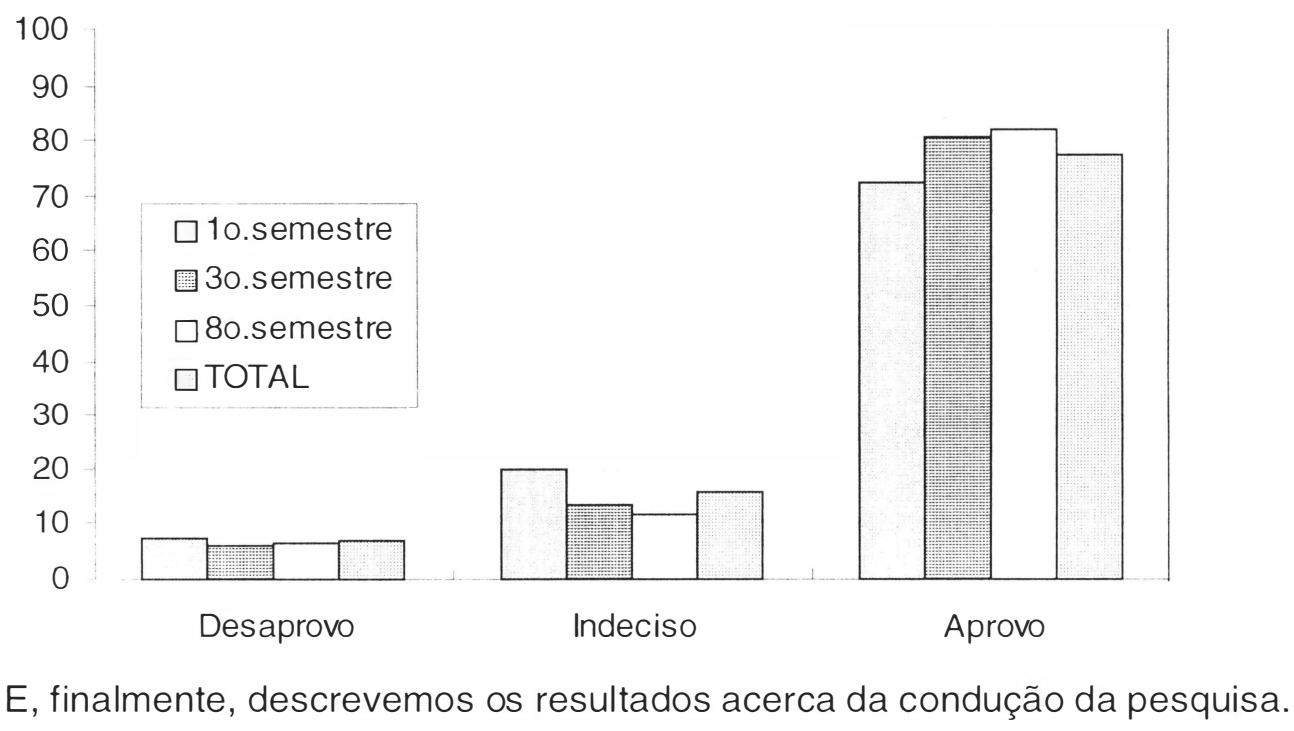




\subsection{CONDUÇÃO DA PESQUISA}

Questionamos ainda os alunos se acreditam que é fundamental ao aluno a prática de investigação científica juntamente com seus professores.

A maioria aprovou tal afirmação, sendo que mais de $83 \%$ dos alunos dos três semestres, acreditam que é fundamental a prática de investigação científica juntamente com seus professores.

Obtivemos os seguintes dados mostrados no Gráfico 4:

GRÁFICO 4: Eu acredito que é fundamental ao aluno a prática de investigação científica juntamente com seus professores.

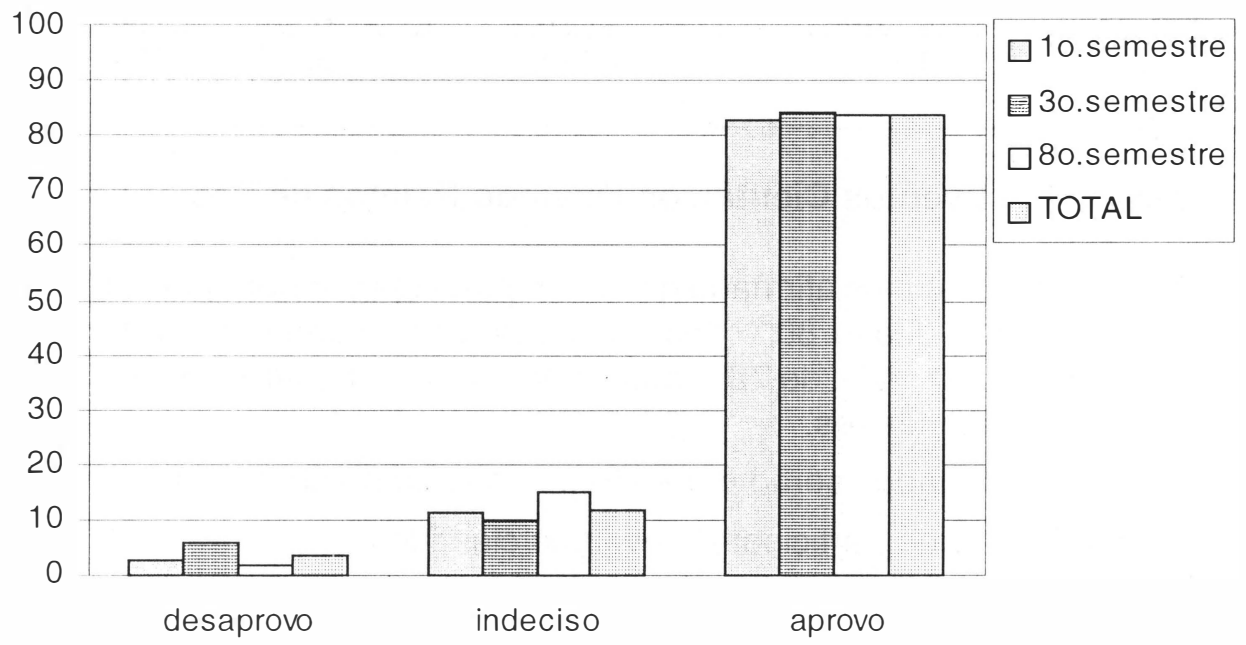

Quanto a afirmação que a pesquisa científica é difícil, complexa e tem de ter curso de mestrado ou doutorado para conduzí-la, a maioria dos alunos desaprovou. Verificamos entretanto que $20 \%$ dos alunos do $8^{\circ}$ semestre aprovaram e no $3^{\circ}$ e $8^{\circ}$ semestres cerca de $10 \%$ dos alunos aprovaram tal afirmação. Havendo, portanto, uma tendência dos alunos do $8^{\circ}$ semestre a acreditar que a pesquisa científica é de difícil condução.

Notamos também, que os alunos do $1^{\circ}$ semestre tiveram o mais alto índice de indecisão. Com relação a isto é aceitável, pois sabemos que eles não tiveram contato com conteúdo de pesquisa e com a condução desta.

Entretanto esperávamos que o maior índice de desaprovação estivesse com os alunos de $8^{\circ}$. semestre. Questionamos o porquê da ocorrência, já que teoricamente os alunos no final do curso deveriam estar mais preparados com relação à pesquisa científica do que no meio do curso. 
Nessa afirmação obtivemos os seguintes dados demostrados no Gráfico 5 abaixo:

GRÁFICO 5: Pesquisa científica é difícil, complexa e tem que ter cursos de mestrado ou doutorado para conduzí-la.

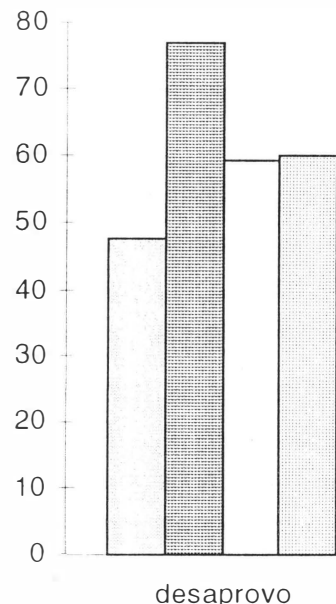

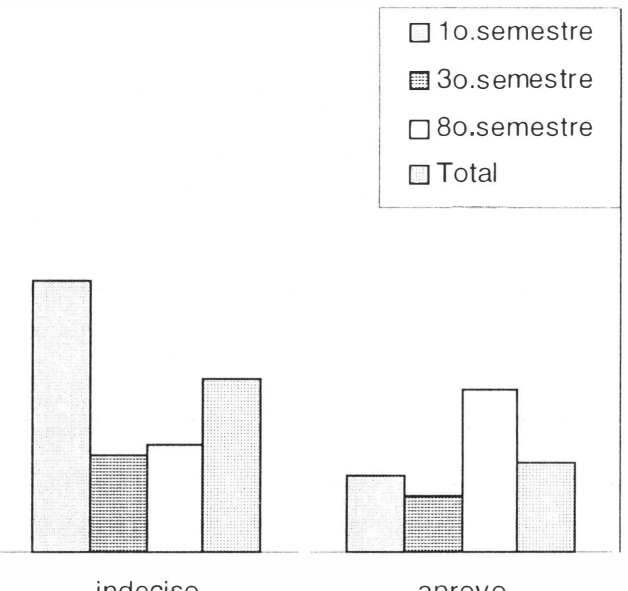

aprovo

Com relação ao auxílio dos professores para conduzirem pesquisa , observa-se que a maioria dos alunos ou estiveram indecisos ou desaprovaram, mostrando assim que não consideram que os professores os auxiliam a realizar as pesquisas.

Observa-se, assim, que talvez a condução de pesquisa ainda não seja percebida pelos alunos, como sendo estimulada no curso de graduação. Analisando os dados por semestre notamos que apesar de haver um crescimento gradativo dos alunos dos três semestres que aprovaram a afirmação estudadas, esse percentual só ultrapassou $50 \%$ no $8^{\circ}$ semestre, sendo que no $1^{\circ}$ semestre mais de $50 \%$ estão indecisos a esse respeito.

Demostraremos os dados na Tabela 5 :

TABELA 5: Meus professores me auxiliam a conduzir trabalhos científicos.

\begin{tabular}{c|c|c|c|c|c}
\hline ESCALA & DESAPROVO & INDECISO & \multicolumn{2}{c|}{ APROVO } & \multicolumn{2}{c}{ TOTAL } \\
\hline & $\%$ & $\%$ & $\%$ & $\%$ & Qtd \\
\hline 1 Semes. & 14,29 & 53,33 & 32,38 & 100 & 105 \\
\hline 3o Semes. & 30,49 & 25,61 & 43,90 & 100 & 82 \\
\hline 8ㅇ Semes. & 24,59 & 50,59 & 50,82 & 100 & 61 \\
\hline $\begin{array}{c}\text { total } \\
\text { (3 semestres) }\end{array}$ & 22,17 & 37,10 & 40,73 & 100 & 248 \\
\hline
\end{tabular}

\section{CONCLUSÕES}

Considerando que os enfermeiros possuem responsabilidade administrativa, assistencial e de promoção e prevenção da saúde, através de orientações e R. Bras. Enferm. Brasília, v. 51, n . 4, p. 589-601 out./dez. 1998 
esclarecimentos ao público, e que a pesquisa ajuda as pessoas a desenvolverem o pensamento lógico, a visão crítica e a rapidez de decisão nas soluções dos problemas, julgamos importante considerar a percepção dos alunos do curso de graduação em Enfermagem com relação à condução da pesquisa, divulgação dos resultados de pesquisa e a conexão entre a prática e os resultados das mesmas.

Face a esta percepção, consideramos imprescindível identificar as atitudes frente à pesquisa científica, comparando a variação da percepção tanto no início, meio e fim do curso de graduação.

Assim, notamos que os alunos do $1^{\circ}$ semestre consideraram que a intuição e a experiência pessoal ainda são mais importantes que os resultados de pesquisas, ou então estiveram indecisos a esse respeito. Alunos do $3^{\circ} e 8^{\circ}$ semestre ao contrário, já consideram mais importante os resultados de pesquisa.

A maioria dos alunos gosta de ler artigos científicos nos três semestres estudados. Entretanto há um declínio entre aqueles que efetivamente lêem os artigos. Quanto a gostar de discutir resultados, de pesquisa com os colegas, houve uma diminuição gradativa da aprovação desse item, sendo o maior índice dos alunos do $1^{\circ}$ semestre com $63,8 \%$, sendo seguido pelos alunos do $3^{\circ}$ semestre e não chegando a $50 \%$ nos alunos do $8^{\circ}$ semestre. Mostrando assim, infelizmente, que não há uma tendência crescente, deste aspecto, entre alunos dos últimos anos, o que sem dúvida irá refletir na sua futura vida profissional, que está próxima.

Os alunos dos três semestres investigados afirmaram gostar de participar de eventos científicos, sendo este item o que mereceu índices maiores de aprovação na escala, pensam que é fundamental ao aluno a prática de investigação científica junto com seus professores, acreditando que pesquisa científica tem relação direta com o cuidado do paciente. Mais de $80 \%$ dos alunos afirmam acreditar na importância da investigação científica.

Em todos os semestres investigados os alunos referiram que não consideram a pesquisa científica difícil, complexa e nem que haja necessidade de curso de mestrado ou doutorado para conduzi-la. Este é, ao nosso ver, um aspecto extremamente positivo que mostra haver uma desmistificação das pesquisas cientificas.

Quanto ao auxílio dos professores para conduzir ação de trabalhos científicos, os alunos do $3^{\circ}$ semestre ficaram indecisos. Os alunos do $8^{\circ}$ semestre em mais de $50 \%$ acreditam que seus professores os auxiliam a conduzir trabalhos científicos.

Evidencia-se que os alunos de $1^{\circ}$ semestre estão menos conscientes da importância dos resultados de pesquisa para o cuidado de enfermagem do que os alunos do $3^{\circ}$ e $8^{\circ}$ semestres, porém mostram mais interesse em discutir resultados de pesquisa com colegas, do que o $3^{\circ}$ e o $8^{\circ}$ semestres. Apesar dos alunos do $8^{\circ}$ semestre terem mais consciência da importância dos resultados de pesquisa e saberem que é fundamental ao aluno a prática de investigação científica, menos da metade gostam de discutir resultados de pesquisa com colegas.

Os resultados deste estudo estão coerentes ao de Harrisson; Louvery; Barley, (1991) que mostrou que há uma progressão na atitude com relação a pesquisa conforme vão progredindo no seu curso de graduação. Interessante destacar que os 
alunos mostram-se interessados na pesquisa e principalmente que não a consideram como algo difícil e inacessível.

Entretanto, é ainda evidente que o foco de suas respostas está centrada na condução das pesquisas, ao nível de avaliação e utilização da pesquisa para o desenvolvimento do conhecimento e da assistência de enfermagem.

Resta ainda enfatizar que pudemos notar, enfim, uma atitude positiva dos alunos na participação de eventos, leitura de trabalhos científicos e na importância da utilização dos resultados para a melhoria da prática clínica.

SUGESTÕES para estudos futuros

Há ainda propostas de estudos, utilizando os dados obtidos nesta investigação, que avaliem comparativamente os resultados com base nas escolas de origem dos estudantes.

\section{AGRADECIMENTOS}

Agradecemos à cooperação da Prof ${ }^{a}$. Dr. ${ }^{a}$ Neusa Costa Alexandre e Prof ${ }^{a}$. Dr. ${ }^{\text {a }}$ Sônia Arantes Almeida, na aplicação dos questionários.

\section{REFERÊNCIAS BIBLIOGRÁFICAS}

1. CARNEGIE, M.E. - The research attitude begins on the undergraduate lesel. Nursing Research, v. 23, n. 2, p. 99, March - April 1974.

2. HARRISON, L.L.; LOWERY, B.; BARLEY, P. Changes in nursing students knowledge about and attitudes toward research following and undergraduate research course. Journal of Advanced Nursing, v.16, p.807-812, 1991.

3. O.M.S. (Org. Mundial de Saúde) - La enfermeria mas alla del año 2000. Informe técnico no 804 de um grupo de Estudio de 1a O. M. S., Ginebra, 1994. 23p.

4. OSPINO, G. C. - Perspectivas de la formacíon de enfermeras en el contexto de $1^{\text {a }}$ meta de salud para todos en el año 2000. Educacion Medica y Salud, V. 25, no 4, p. $370-377,1991$.

5. PADILHA, M. T. C. S.; CARVALHO, M. T. C. - O aluno de graduação e a Pesquisa científica. Rev. Esc. Enferm. USP, v27, nº 2, p. 281-295, ago. 1993.

6. RICCI, W. Z.; CASSIANI, S. H. B. - Opiniões de Universitários da Enfermagem e Farmácia acerca da pesquisa científica. In.: SIMPÓSIO DE INICIAÇÃO CIENTíFICA DA USP, 2., 1994, Ribeirão Preto, Anais... São Paulo, 1994.

7. RODGERS, B. L.; COWLES, K. V. - The advancend practium project. Nursing Outlook, v. 38, n 1, p. 31-35, Jan/Fev. 1990. 